\title{
THE ROLE OF ANIMATION IN DEVELOPING THE ENVIRONMENTAL AWARENESSOF THE ARAB CHILD
}

\section{Ahmed Sayed Hammouda El-Sayed *}

${ }^{1}$ Department of Advertising, Higher Institute of Applied Arts, 6 October, Egypt

\begin{abstract}
The issue of the environment and its protection are the talk of the hour, especially after the voices calling for the need to protect and develop the environment because of the irresponsible behavior of mankind, which is the first environmental problem. Order and lack of concern for health, hygiene, etc. The best solution to preserving the environment lies in a person's upbringing and childhood, the most important stage in which his vulnerability to the various factors surrounding him increases, which affects the formation of his personality throughout his life. Here, the role of animation is evident in environmental awareness, which effectively contributes to environmental awareness, because animated films play a great benefit in conveying reality to the child and the movement, vitality and credibility it gives. Previous research and studies in the field of childhood have shown that there is a severe lack of environmental awareness among pre-school children, the behaviors that indicate their environmental awareness, and this may be a result of the lack of audiovisual means accompanying the information they obtain, as they are in great need to modify their behaviors in line with their environment. Therefore, the research deals with the role of animation in environmental awareness and extension programs, as it is an important tool to raise environmental awareness and has a significant impact on directing the Arab child in a positive and effective manner

\section{Introduction :}

It is imperative to work with children from an early age to raise their awareness of environmental issues and help them understand our responsibility to use the resources we have wisely. As we know habits are formed as early as we can, by working with children, to influence decisions made by their families on environmental issues. Within the framework of the comprehensive school community setting, working with pupils, parents and teachers to enhance their understanding of environmental issues through workshops, interactive activities and training is an essential component of success by focusing on awareness of the appropriate management of the basic environment elements to conserve energy, water and soil and methods of solving some Environmental problems such as waste and pollution at an early age and within the context of the school community and the home as a whole, tremendous progress is made as

\footnotetext{
*Corresponding author: author@institute.xxx
} 
a result of early understanding, behavior change and subsequent improvements in the choices people make as well as the systems in place to support these choices.

It should be noted that by arming children with knowledge and understanding to reduce consumption, reuse and recycle, changes occur naturally in the home and then extend further in the workplace of parents. As long as students of all ages understand why we need change, and it is part of the rethinking process, then we can get future generations to truly care about the world around them. Awareness for children and school students: Schools play a major role in all processes of environmental awareness for students and children and their effective role in achieving the vision and strategic directions of countries aimed at increasing focus on environmental education and awareness and community participation in this, which helps to support children's association with their environment and develop empathy towards the world The natural they live.

\section{Research problem:}

The research problem lies in the following question:

How can the environmental awareness of the Arab child be developed through animation?

First: The level of awareness of environmental issues and problems: This includes developing children's awareness of the following topics:

1- The extent of the impact of human activities on the state of the environment in a positive or negative way.

2- The extent of the effect of the individual's behavior (such as burning waste, smoking / cutting trees, depleting water ... etc.) on the natural balance in the environment.

3- The importance of concerting individual, local and international efforts to solve environmental problems. 
4- The link between local environmental problems and regional and global environmental problems and the necessity for cooperation between peoples to solve these problems.

Second: the level of environmental knowledge of environmental issues and problems:

It includes helping children acquire the following:

1- Analyzing the information and knowledge necessary to identify the dimensions of environmental problems that affect humans and the environment.

2- Linking the information obtained by the student from the various fields of knowledge with the field of studying environmental problems.

3- Understanding the consequences of bad use of natural resources and its effect on depletion and depletion of these resources.

4- Knowing the historical background behind the current environmental problems. Learn about local, regional and international efforts to protect and preserve the environment.

Third: the level of environmental tendencies, trends and values: - It includes providing children with appropriate opportunities that help them to:

Developing appropriate positive tendencies to improve and preserve the environment.

- Formation of appropriate directions towards combating environmental problems and preserving and protecting their resources from the environmental dangers.

Developing a sense of individual and collective responsibility in protecting the environment through teamwork and collective participation in solving environmental problems.

Building environmental ethics and values such as respecting the right to continue in all environments and respecting private and public property in a way that directs students' behavior towards commitment to their responsibility for the environment and commitment to it. 
Fourth: Environmental Skills Level: This includes helping children develop the following environmental skills:

1- Collecting environmental data and information from research sources, experiments, field work, environmental monitoring, observation, experimentation and investigation.

2- Organizing, classifying, representing and analyzing data, and using various methods of research, investigation and presentation.

3- Developing an action plan to solve environmental problems or maintain and develop natural resources, or rationalize their consumption and protect them from depletion and consumption, so that this plan includes work procedures and their quality with scheduling in time and place.

4- Extrapolating facts from studying environmental problems, then formulating models, generalizations, or laws about them.

5- Organizing studies in environmental monitoring and environmental experiments and building development projects based on the results of this monitoring.

Fifth: The level of participation in environmental activities: - It includes providing appropriate opportunities for children to contribute to the following:

1- Participation in surveys, reviews and environmental studies in order to suggest solutions to these problems.

2- Organizing activities for environmental protection, maintenance and development of its resources, whether at the individual level or at the group level.

3- Evaluating environmental programs, decisions and procedures in terms of the degree of their impact on the level of balance between the requirements of human life and the requirements of preserving the environment. 
4- Participation in national, regional and global environmental activities, projects and campaigns.

Characteristics and characteristics of environmental education:

1- Environmental education tends to reduce the effects of environmental problems and help individuals to realize them.

2- Environmental education takes an inclusive approach to several scientific branches in dealing with environmental problems.

3- Environmental education is characterized by the nature of continuity, looking to the future and addressing its issues.

4- Environmental education links society and its institutions with environmental protection legislation.

5- Environmental education clarifies complex problems and provides knowledge to clarify them and identify their causes.

Principles of environmental education approved by international conferences:

1- The individual has the right to enjoy life, freedom, education, and the enjoyment of the environmental resources he needs in his life.

2- Environmental education is a lifelong process through the formal system and the informal system.

3- Teaching the environment with all its natural, technological, cultural, historical, ethical and aesthetic elements through educational curricula. 
4- Defining educational curricula for environmental education that are consistent with the nature of the educational phase, and paying attention to the learning environment in the early stages.

5- Discovering environmental problems, identifying their real causes, and working to address them using environmental education methods.

6- The use of different educational methods and a large number of effective teaching methods in environmental education.

7- Linking scientific research and its results with environmental education curricula.

8- Local, regional and international cooperation in dealing with environmental problems.

The advantages of animation on environmental education for the Arab child:

These films and mentions instill new interests that have an impact on the child's behavior, the formation of his habits and values, and gain him experiences and knowledge, especially at this young age when he is ready to receive and learn a lot and much. The animation contains anecdotes that can help the child understand the nature of social relationships and give him various environmental skills and experiences, such as issues of waste recycling, food pollution, pollution using plastics, and issues of preserving natural reserves, and help inculcate scientific thinking and encourage him to pay attention to the environment, which has become a feature of the era. It fulfills some of the child's psychological needs and satisfies his curiosity instinct. It makes him seek to explore what is new in his environment, develop the child's imagination, nurture his abilities, and introduce him to multiple innovative methods of preserving and respecting the environment. 


\section{Results :}

1- Considering animation as an educational advertisement tool for children and growing up as an effective means in achieving the goals of environmental awareness and extension for them, and its societal spread is an indicator of the possibility of using it in the field of environmental awareness advertisements as a successful method.

2- The link between the successes of the advertising message for the cartoon ads prepared for children for the purpose of raising environmental awareness and how to employ them on the appropriate means in order to achieve interaction and make the required response.

3- The tendency to employ cartoon advertisements for environmental awareness specially prepared for children is considered an intellectual and design direction that takes it out of the stereotypical space to open new horizons in the field of environmental awareness and guidance.

Recommendations:

1- The positive role of using animation in spreading environmental awareness among children from their earliest years.

2- Applying patterns of behavioral modification and change towards environmental issues, respecting and applying them by providing advertisements based on animation that are well thought out and planned to work on the behavioral and directional development of society.

\section{References}

1- http://www.envirocitiesmag.com/articles/enviromental-educationandawareness/urgency-of-environmental-education.php

2- https://www.ecomena.org/environmental-education-ar/

3- http://www.envirocitiesmag.com/articles.com

4- http://www.rudaw.net/arabic/opinion/301120141 
5- http://byotna.kenanaonline.com/posts/86982

6- https://www.facebook.com/smcc.idmaj/posts/

7- http://elaalim1989.ahlamontada.com/t76-topic

8- http://dspace.univ-tebessa.dz/bitstream/handle/123456789

Received: May 15, 2018

Accepted: July 10, 2018 